PINHOLE IMAGING OF LASER-PRODUCED THERMONUCLEAR ALFHA PARTICLES

Kenneth M. Brooks, Natale M. Ceglio, Vincent W. Slivinsky. Harlow G. Ahl strom, Erik K. Storm, Harry N. Kornblum and George R. Leipelt

November 1, 1977

This paper was prepared for submission to the APS Plasma Physics Meeting of the American Physical Society, Atlanta, Georgia, November 5-11, 1977

This is a preprint of a paper interided for publication in a journal or proceedings. Since changes may be made before publication, this preprint is made available with the understanding that it will not be cited or reproduced without the permission of the author.

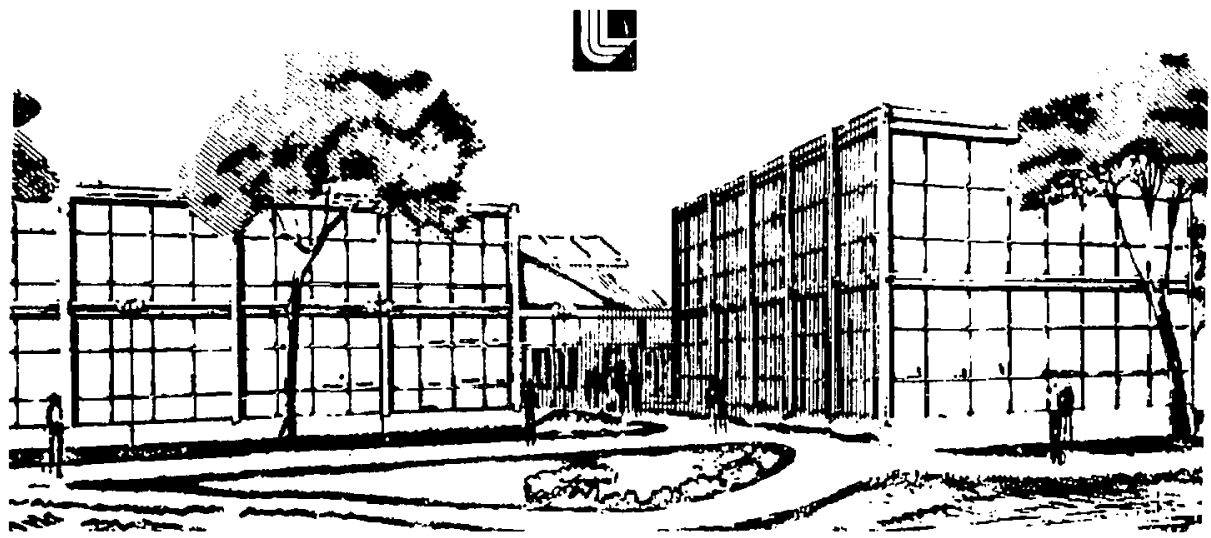


Abstract Submitted

for the APS Plasma Physics Mecting of the

American Physical Society

November 5-11, 1977

Physics and Astronomy Classification Scheme Number 52
Bullet in Subject Heading in which Paper snould be placed

Laser Fusion

Pinhole Imaging of Laser-Produced Thermonuclear Alpha Particles. Kenneth M. Brooks, Natale M. Ceglio, Vincent W. Slivinsky, Harlow G. Ahistrom, Erik K. Storm, Harry N. Korriblum and George R. Leipelt, Lawrence Livermore Laboratory. ${ }^{*}$--Results of pinhole images of thermonuclear alpha particles generated by exploding pusher targets in the Argus laser facility are reviewed. Recorded images indicate that the reactions occur within a 25 to 30 micron region with twelve micron resolution for ten micron pinholes and thirty micron resolution for twenty-five micron pinholes. These results are in good agreement with LASNEX computer predictions and are confirmed by Zone Plate imaging of the burn conducted by Natale M. Ceglio at LLL. Planned three-dimensional imaging of the burning $D-T$ gas in the Shiva laser facility using seven micron pinholes is discussed. Higher yields ( $\sim 5 \times 10^{10}$ reactions) and three orthogonal images of the burn will provide a data base for analysis using an Algebraic Reconstruction Tecnnique to provide a higher resolution ( 9 micron), three-dimensional view of the burn. **Supported by $U$. S. ERDA Contract $W-7405-E N G-48$

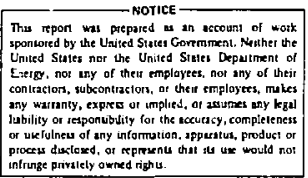

Submitted by

The repon wal prepors as an scoun al work

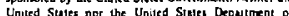
Exergy, no: uny of then maptayes, not any of thesi 


\section{PINHOLE IMAGING OF LASER-PRODUCED THERMONUCLEAR ALPHA PARTICLES}

Kenneth M. Brooks, Natale M. Ceglio, Vincent W. Slivinsky Harlow G. Ahlstrom, Erik K. Storm, Harry N. Kornblum and George R. Leipelt

\section{Alpha Particle Imaging Results}

\section{S1 ide \#1}

Schematic of the Argus laser system -

a) Describe experimental parameters.

b) Describe results - exploding pusher giving $6 \times 10^{8}$ reactions. Slide \#2

Primary exploding pusher emissions -

a) Brief run-through of emissions.

b) Experiments to image burning D-T gas using $3.52 \mathrm{MeV} \alpha$ particles first completed in November 1977. Prel iminary report of those results were given at last year's APS meeting.

STide \#3

Photo of one pinhole camera apparatus -

a) Describe significant parts - pinhole array of 10 and $25 \mu \mathrm{m}$ pinholes.

b) 2/10 mil Tantalum filter.

c) $6 \mu \mathrm{m}$ thick $\mathrm{CN}$.

slide \#4

Filter - detector response to Argus exploding pusher emissions -

a) point out ion, electron, $x$-ray, $\alpha$, neutron and photon distributions and describe how each is absorbed and/or passed in/through the detector-fil ter system. 


\section{Stide \#5}

Imaging geometry -

a) allows determination of $R_{0}$, the object radius, from $R_{1}$, the observed image radius even though a large pinhole is used.

b) resolution of the system is defined as $s / m$ where $s$ is the possible spread of a particle tracks in the image plane that originated from a point source in the object plane.

c) resolution for 10 micron pinholes with a magnification of four is 125 microns and for 25 micron pinholes in the same camera is 31 microns.

STide \#6

Lines representing the spatial transformation from image to object planes for 10 and 25 micorn pinholes in a camera with $m=4$.

a) Emphasize that although the transformation is linear, it is displaced and there is no one-to-one spatial mapping from image to object planes.

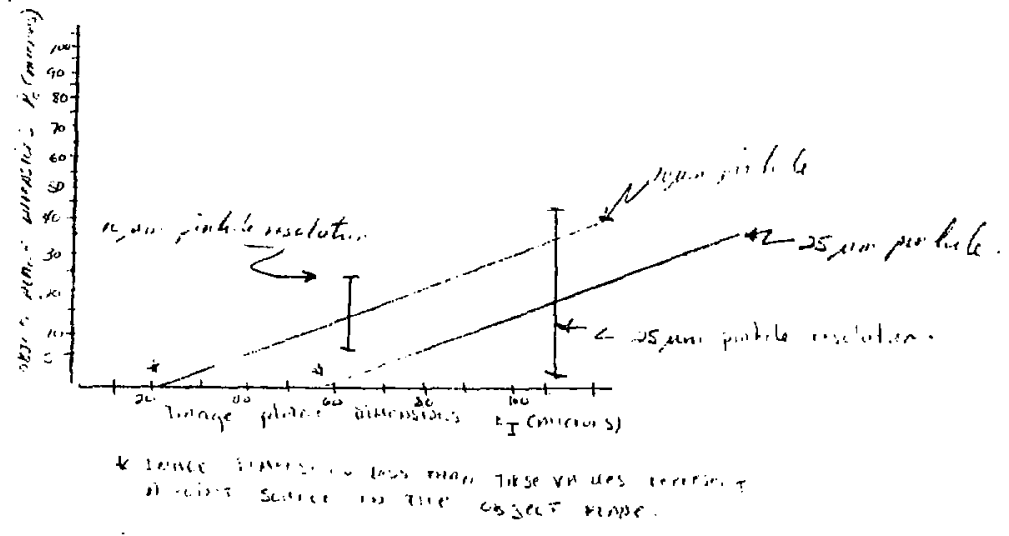


Slide \#7

Photo of an Imaged Hyperion target -

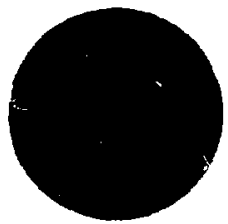

(a)

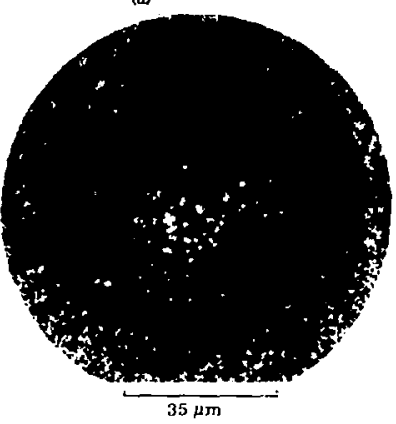

(b)
a) point out the low background.
b) tracks have very definite
characteristics and are easily
distinguished from background noise such as film scratches.

FIG. 3. $\alpha$-particle tracks (a) without pinhole and $(b)$ with pinhole. The diameter of the $\alpha$-particle image is referenced to the object plane. 


\section{slide \#8}

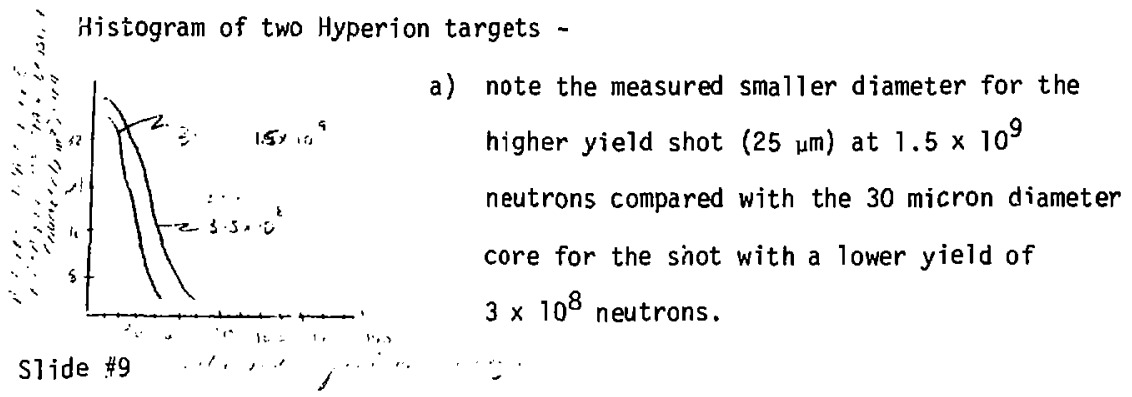

Superposition of the recorded alpha image for the high yield shot (25?209 07) and the Lasnex calculation for the burn at approximately the same angle.

a) The Lasnex calculation has been spatially transfcrmed into image plane space.

b) Resolution at this yield and pinhole size does not allow us to see Jetail in the object.

\section{S1ide $\# 10$}

Picture of Shiva -

str. $f^{\prime}$ a) next step will be to reduce the pinhole size to 7 microns in Shiva which is expected to produce $>10^{10}$ reactions.

\section{Slide \#11}

What comes out of Shiva

a) x-ray spectra is from :asnex 2-0 calculations.

b) we will absorb $1 / 10$ Joule of energy in the filter which will raise

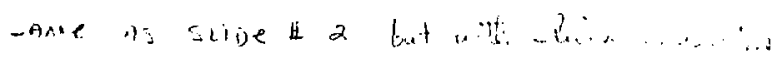


its temperature to $86^{\circ} \mathrm{K}$ which will not decrease its sensitivity significantly.

c) All other emissions, though greater in magnitude, will be absorbed/ passed in the same manner as those encountered on Argus.

d) Using three of these cameras placed on orthoganal axes, we hope to produce a three-dimensional image of the burn with a nominal resolution of 9 microns. This will be accomplished using an Algebraic Reconstruction Technique such as described by Huebel and Tuntz in UCRL 77450.

Reference to a company or product name does not imply approval or recommendation of the product by the University of California or the U.S. Department of Energy to the exclusion of others that may be suituble.

NOTICE

"This report was prepared as an account of work sponsored by the United States Government. Neither the United States nor the United States Energy Research \& Development Administration, nor any of their employces, nor any of their nor any of their employces, not any of their makes any wairanty, express or implied, or assumes any legal linbility or responsibility for the accuracy, completeness or usefulness of any information, apparatus, product or process information, apparatus, product or process
disclosed, or represents that its use woutd not infringe privately-awned rights." 


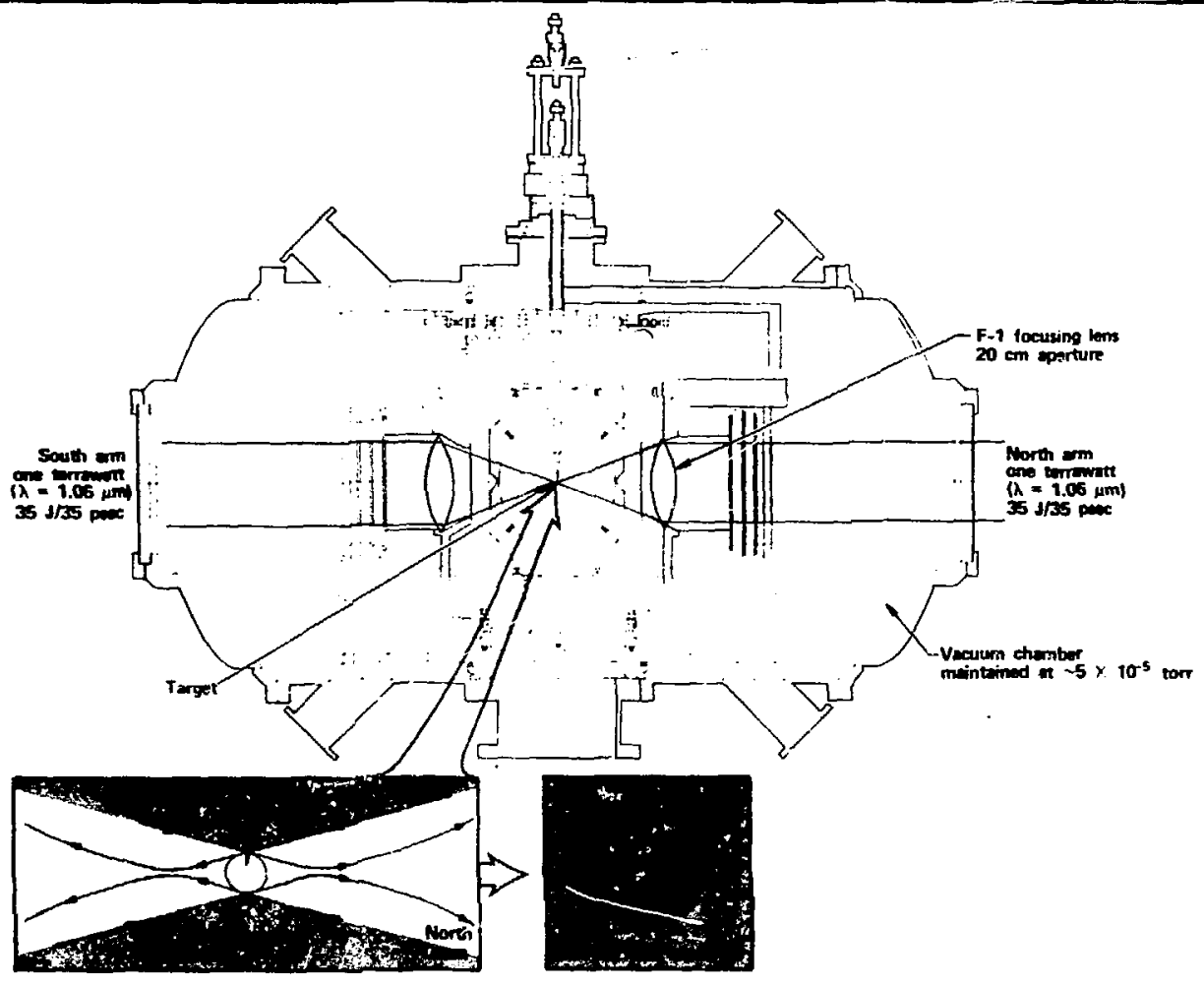




\section{PRIMARY EXPLODING PUSHER EMISSIONS}

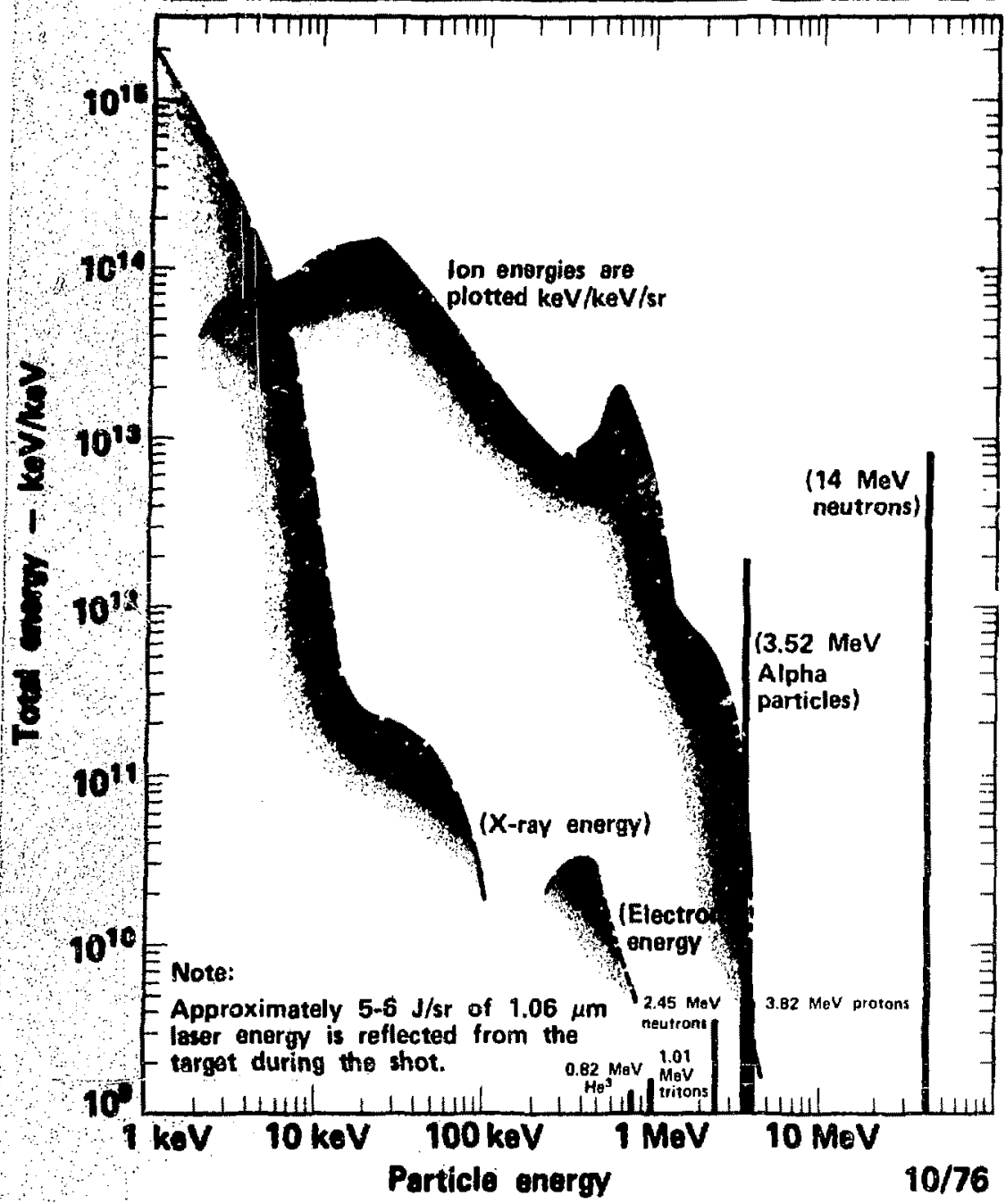




\section{ALPHA PIN HOLE IMAGE OF HYPERION TARGET}
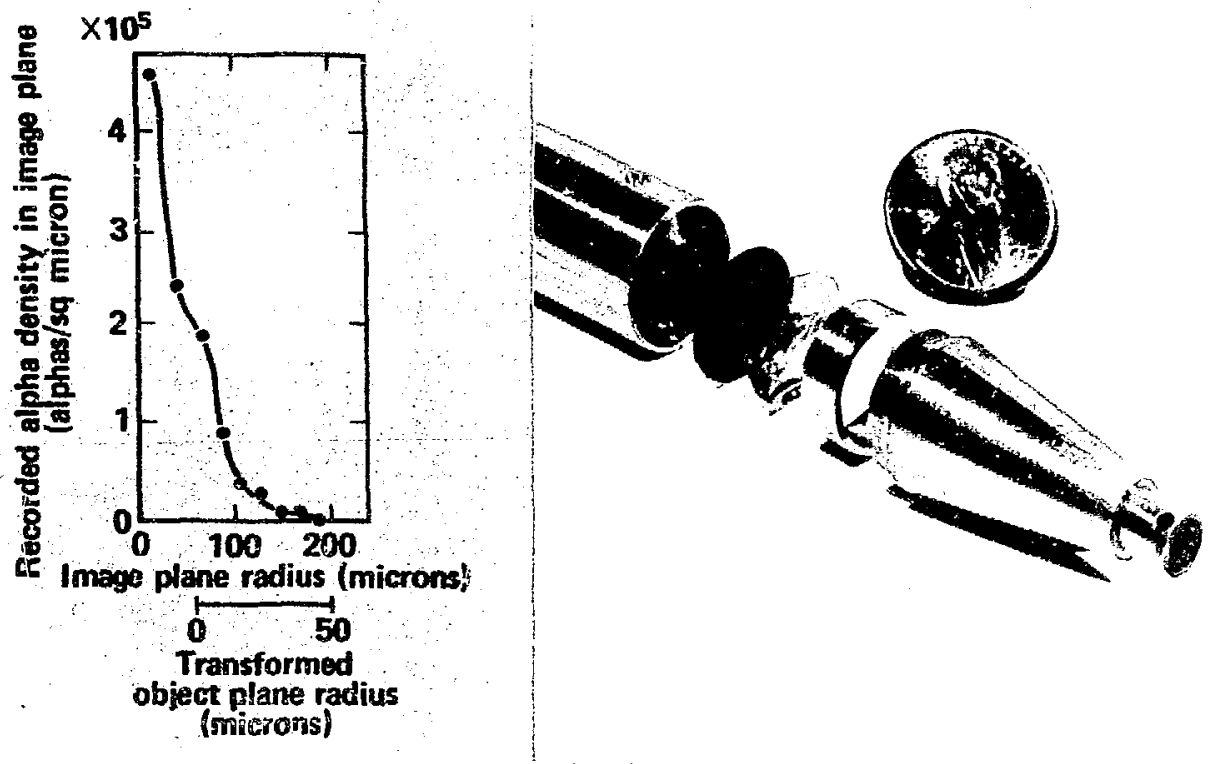
FILTER-DETECTOR RESPONSE TO ARGUS EXPLODING

PUSHER EMISSIONS

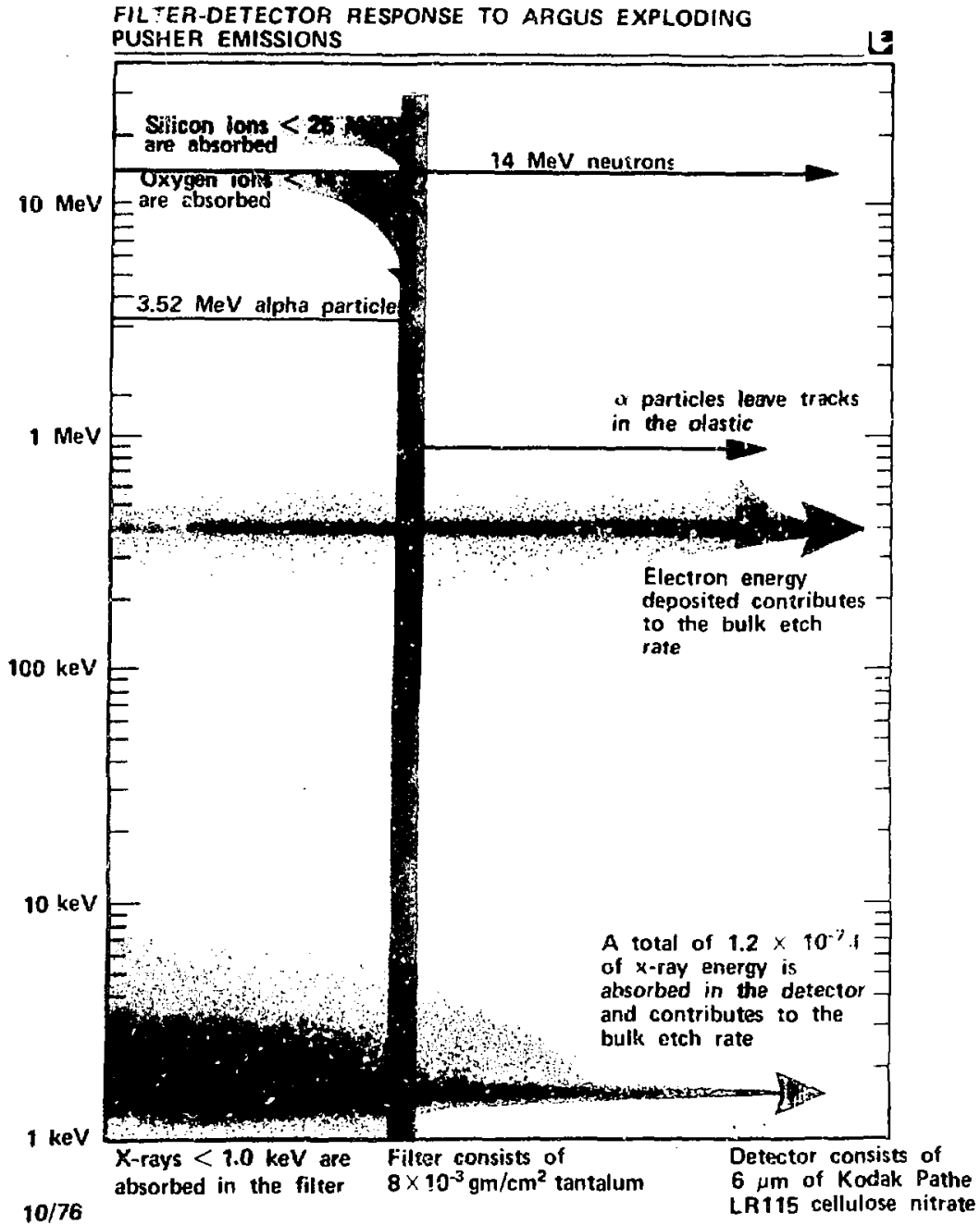

Figure 4 


\section{ALPHA IMAGING GEOMETRY}

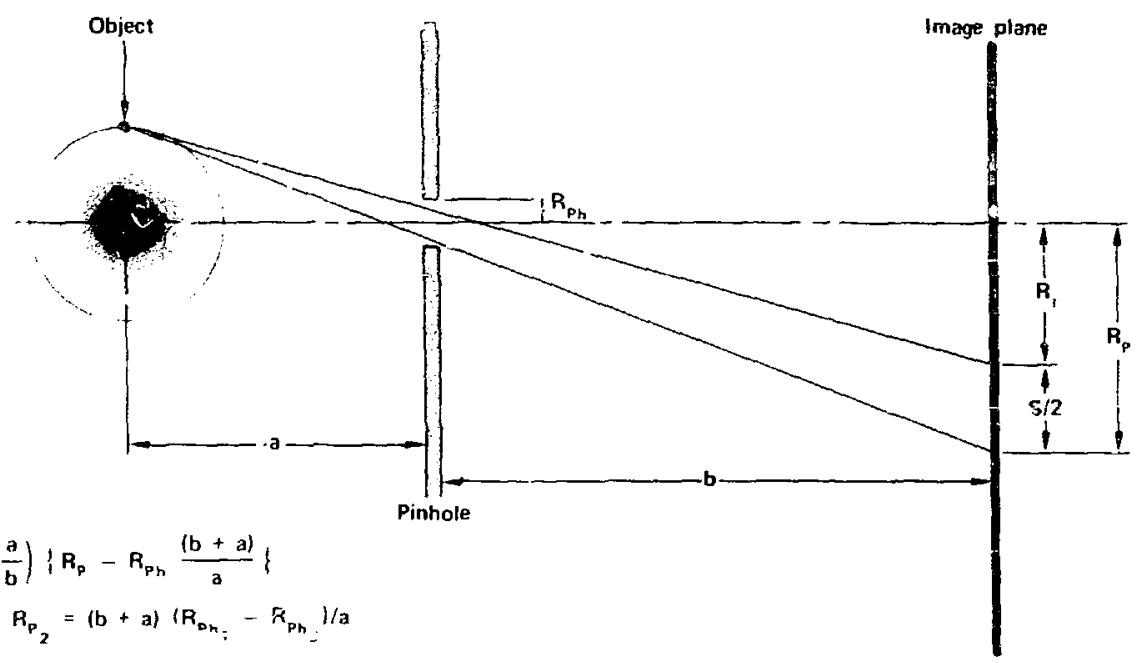

(3) $\left(R_{P_{\text {B }}} / R_{P_{2} 2}\right)^{2}=$ (alpha density, /alpha density ${ }_{2}$ )

Geometry for determining the spread $(s)$ of alpha particles in the image plane oridinating at a point source in the object plane where

\author{
$a=$ object destance \\ $b=$ image distance \\ $R_{P_{h}}=$ pinhole radius \\ $R_{1}=$ true image radius for an infinitely small pinhole
}

$S=$ the spread of a point source in the vbject plane propected anto the im.zge plane

$R_{p}=$ the radius of the exptcied image

$R_{0}=$ the true object radius 